\title{
Reseña de las XI Jornadas de Comunicación de Investigación en Filosofía (FHUC - UNL)
}

\section{Manuel Berrón \\ María Guadalupe Mettini María Sol Yuan}

Las "Jornadas de Comunicación de Investigación en Filosofía" son organizadas por el Departamento de Filosofía de la Facultad de Humanidades y Ciencias de la Universidad Nacional del Litoral y se desarrollan de manera continua desde el año 2000. Este evento convoca a investigadores, docentes del área y estudiantes avanzados de la Universidad Nacional del Litoral y de las universidades de la región, entre las cuales se destacan la Universidad Nacional de Entre Ríos y la Universidad Nacional de Rosario.

Los días 1 al 3 de diciembre de 2011 tuvo lugar la XI edición de las Jornadas, centradas en la temática: "Verdad, lenguaje y acción: problemas en torno al conocimiento y la sabiduría", con el auspicio de la Agencia Nacional de Promoción Científica y Tecnológica, el Consejo Nacional de Investigaciones Científicas y Técnicas y Tópicos. Revista de Filosofía de Santa $F$ e. La misma agrupó cincuenta y dos participaciones en mesas en torno a temáticas comunes, cuarenta y cuatro exposiciones individuales, una conferencia, un taller y un espacio destinado a la presentación de libros y revistas del ámbito filosófico, a lo cual podrían sumarse las contribuciones del "I Simposio Nacional de Filosofía Antigua", que se desarrolló de manera simultánea.

La conferencia central, titulada "¿Reducibilidad de la economía a la física? Hacia la desaparición de la economía descriptiva”, estuvo a cargo del Dr. Ricardo Gómez. El conferencista abordó de forma sólida y amena un tópico de eminente carácter teórico pero con serias consecuencias en el plano ético y, naturalmente, económico. Repasando la discusión erudita del siglo XX sobre la fundamentación epistemológica de la física exhibió el modo en que los principales economistas pretendieron asimilar estas dos 
disciplinas reduciendo la segunda a la primera. Su trabajo consistió en mostrar precisamente la irreductibilidad que existe entre estos campos del saber utilizando como estrategia principal las limitaciones metodológicas de la física.

Las mesas temáticas representan la participación mayoritaria dentro de las Jornadas. En ellas se desarrollan los resultados parciales del trabajo de diversos grupos de investigación enmarcados dentro de proyectos pertenecientes a universidades y centros de investigación a nivel nacional. Son numerosos los tópicos trabajados en este contexto, entre los cuales podríamos mencionar, por citar algunos ejemplos, las problemáticas en torno al lenguaje, la lógica matemática y la epistemología contemporánea, reunidas en el proyecto "Lenguaje universal, ciencia unificada y enciclopedia", bajo la dirección de Adriana Gonzalo; el proyecto "Razones y pasiones en Ética y Política", dirigido por Graciela Vidiella, que se ocupa de cuestiones relativas a la discusión contemporánea en torno a la democracia deliberativa, la relación entre racionalidad y pasiones y las posibles soluciones a conflictos morales y jurídicos; y el proyecto "Conocimiento y libertad. El ideal de la sabiduría clásica en el pensamiento moderno" bajo la dirección de Fernando Bahr, algunos de cuyos resultados se presentaron en la mesa titulada "Sabiduría, escepticismo y praxis liberadora: de Michel de Montaigne a Friedrich Nietzsche”.

Esta edición de las Jornadas contó, además, con un Taller sobre la enseñanza de la Filosofía, a cargo de Ana Couló (docente en la Cátedra "Didáctica de la Filosofía" en la Facultad de Filosofía y Letras de la Universidad de Buenos Aires). Participaron de él docentes de la escuela media y del nivel superior y estudiantes de la Carrera de Filosofía. La finalidad del mismo fue construir un vínculo entre la escuela media, los institutos de formación docente y la universidad. Las temáticas tratadas giraron en torno a la anomalía disciplinar de la filosofía, los criterios de evaluación de una buena clase y las experiencias alternativas a la enseñanza formal de la filosofía.

También fue importante la realización del "I Simposio Nacional de Filosofía Antigua". El mismo sirvió de espacio para el encuentro de cuatro 
grupos de investigación (enmarcados en proyectos PIP - CONICET) dirigidos por Fabián Mié, Claudia Mársico, María Angélica Fierro y Gabriela Rossi. En virtud de ello, hubo cuatro grupos temáticos denominados: "Élenchos", "Psicología y marcos textuales", "Significado y conocimiento" y "Ética y ontología". El hecho es destacable por ser el primero de su naturaleza en nuestro país.

Por ultimo, resulta de interés resaltar el espacio destinado a la difusión de revistas académicas y libros. Entre las revistas, se presentaron los nuevos números de Tópicos. Revista de Filosofía de Santa Fe y Cuadernos de Filosofía; entre los libros, Experiencia y Concepto: intensidades clásicas y tensiones contemporáneas, compilado por Diana López, María Sol Yuan y Cecilia Lammertyn, y Las filosofías de la revolución. Mariano Moreno y los jacobinos rioplatenses en la prensa de Mayo: 1810-1815, de Silvana Carozzi.

Las Jornadas de Comunicación de Investigación en Filosofía publican periódicamente una selección de los trabajos presentados. Para recibir información acerca de esta publicación y del evento en general comunicarse con: jcfilounl@yahoo.com.ar. 